\title{
Promotion of women's mental health: the influence of physical health and the environment
}

\author{
Promoção da saúde mental de mulheres: a influência da saúde física e do meio ambiente
}

Promoción de la salud mental de las mujeres: la influencia de la salud física y el medio ambiente

\section{Jacqueline de Souza' \\ ORCID: 0000-0002-6094-6012 \\ Jaqueline Lemos de Oliveira' \\ ORCID: 0000-0003-3699-0280}

Jordana Luiza Gouvêa de Oliveira' ORCID: 0000-0001-5905-8993

Letícia Yamawaka de Almeida' ORCID: 0000-0002-5192-6052

Loraine Vivian Gaino' ORCID: 0000-0002-2074-909X

Denise Marie Saint-Arnault" ORCID: 0000-0002-4436-8347

Universidade de São Paulo. Ribeirão Preto, São Paulo, Brazil. "Universidade de Michigan. Ann Arbor, Michigan, United States of America.

How to cite this article: Souza J, Oliveira JL, Oliveira JLG, Almeida LY, Gaino LV, Saint-Arnault DM. Promotion of women's mental health: the influence of physical health and the environment. Rev Bras Enferm. 2019;72(Suppl 3):184-90. doi: http://dx.doi.org/10.1590/0034-7167-2018-0415

\section{Corresponding Author:} Jaqueline Lemos de Oliveira E-mail: jaquelemos@usp.br

Approval: 08-14-2018

\section{ABSTRACT}

Objective: To describe the results of a group of women's mental health promotion conducted by nurses. Method: This is a quantitative study of the pre- and post-test type. The participants were women aged between 20 and 64 years old attending a Primary Care Unit. We used the Sarason Social Support Questionnaire, the World Health Organization Quality of Life Assessment questionnaire, and the Rosenberg Self-Esteem Scale. Data were collected before, immediately after and three months after the intervention. Results: improvement in the physical and environmental quality of life was identified. However, there was no measurable change in the other indicators adopted. Conclusion: the ludic activities and the Body Mapping technique were promising for improving the physical and environmental domain of quality of life, constituting important tools for nursing care and interventions related to mental health in basic care.

Descriptors: Mental Health; Women; Health Centers; Primary Health Care; Quality of Life.

\section{RESUMO}

Objetivo: descrever os resultados de um grupo de promoção à saúde mental de mulheres, conduzido por enfermeiras. Método: trata-se de um estudo quantitativo do tipo pré e pósteste. As participantes foram mulheres entre 20 e 64 anos atendidas numa Unidade de Atenção Básica. Utilizou-se o Questionário de Suporte Social de Sarason, o questionário de Avaliação de Qualidade de Vida da Organização Mundial da Saúde e a Escala de Autoestima de Rosenberg. Os dados foram coletados antes, imediatamente depois e três meses após a intervenção. Resultados: foi identificada melhoria no domínio físico e do meio ambiente da qualidade de vida, contudo não houve alteração mensurável nos demais indicadores adotados. Conclusão: as atividades lúdicas e a técnica de Body Mapping se mostraram promissoras para melhoria do domínio físico e do meio ambiente da qualidade de vida, constituindo importantes ferramentas para o cuidado de enfermagem e intervenções relacionadas à saúde mental na atenção básica.

Descritores: Saúde Mental; Mulheres; Centros de Saúde; Atenção Primária à Saúde; Qualidade de Vida.

\section{RESUMEN}

Objetivo: describir los resultados de un grupo de promoción de la salud mental en mujeres, dirigido por enfermeras. Método: se trata de un estudio cuantitativo del tipo pre-test y posttest. Las participantes fueron mujeres entre 20 y 64 años atendidas en una Unidad de Atención Básica. Se utilizó el Cuestionario de Apoyo Social de Sarason, el cuestionario de Evaluación de la Calidad de Vida de la Organización Mundial de la Salud y la Escala de Autoestima de Rosenberg. Los datos se recolectaron antes, inmediatamente después y tres meses después de la intervención. Resultados: se identificó una mejora en el dominio físico y del medio ambiente de la calidad de vida, sin embargo no se registraron cambios mensurables en los demás indicadores adoptados. Conclusión: las actividades lúdicas y la técnica de Body Mapping resultaron alentadoras para la mejora del dominio físico y del medio ambiente de la calidad de vida, constituyendo herramientas importantes para el cuidado de enfermería e intervenciones relacionadas a la salud mental en la atención básica.

Descriptores: Salud Mental; Mujeres; Centros de Salud; Atención Primaria de Salud; Calidad deVida. 


\section{INTRODUCTION}

Mental health promotion is described as a set of actions that aim, through an empowerment process, to create individual, social, and environmental conditions that allow individuals to increase their ability to control their own lives. Therefore, promoting mental health implies the use of strategies that foster supportive environments and strengthen individuals' resilience, showing respect for culture, prioritizing equity, social justice, personal dignity, and interconnections ${ }^{(1-3)}$.

Although health and mental health promotion are complementary approaches, health promotion generally focuses on lifestyle factors (promoting physical activity, healthy lifestyle habits, reducing substance use), while promoting mental health aims to directly increase resilience and empower people to better cope with adversity or stressful events by focusing on cognitive, social, and emotional skills, primarily using strategies based on problem solving, social skills training, and social support ${ }^{(1-3)}$.

Thus, in spite of such complementarity, specific efforts are recommended to promote mental health, since promoting health, in general, may focus on multiple health areas and the variables that affect it, however, there is a great possibility of ignoring the specific aspects of mental health in this process, that is, the promotion of mental health focuses exclusively on the mental health outcomes of the individual, which will, therefore, have an impact on their overall health ${ }^{(2)}$. Thus, an important issue for nursing practice is set up.

It should be emphasized that the promotion of mental health has been defended as one of the priorities for the construction of public policies at the global level and, therefore, it is recommended to integrate this approach in the setting of primary health care ${ }^{(1,3)}$. However, a review study has pointed out that little research on mental health promotion has been developed in this setting ${ }^{(1)}$.

Many are the strategies used both for the rehabilitation of people with mental disorders and to promote the mental and physical health of individuals, one of them is psychosocial intervention, which enables the confrontation of personal problems, re-signification of suffering and the discovery of potentialities ${ }^{(1-2)}$. Studies on the effectiveness of these interventions have been developed in Iran, the United States, Canada, Tanzania, Haiti, and Japan ${ }^{(4-11)}$.

In general, the population of these studies was individuals with some chronic disease such as cancer, HIV, and mental disorders ${ }^{(4,6-7,10-11)}$. Few of these studies addressed individuals in the general population without specific morbidity ${ }^{(1,8)}$. Thus, the settings of these studies were mostly clinics and hospitals $s^{(4,6-7,9-11)}$, so that few were developed in the community ${ }^{(8)}$.

It should be emphasized that an important recommendation on the promotion of mental health is that it is addressed not only to subgroups with significant risks but also to the general population (universal character) ${ }^{(2)}$. Thus, undertaking such actions with adult women is important, given that the major part of this population is of workers of whom children and the elderly are often dependent. Moreover, psychic suffering in this group may limit their daily-life activities, predisposing the individual and the social environment to a vicious circle of risks and social vulnerability ${ }^{(2)}$.
Among adults, women are a relevant subgroup because they are generally more vulnerable to some mental disorders due to life cycle experiences, hormonal influences, vulnerability to violence and exploitation in relationships, cultural factors, and gender discrimination. Besides, they are more likely to be carers for their family, and in addition, the emotional and financial dependence associated with lack of empowerment are important factors that restrict their choices in life, strongly impacting their mental health ${ }^{(2)}$.

Previous research, whose participants were specifically adult women, also generally adopted groups with specific morbidity or condition, such as cancer, HIV, pregnancy, ethnicity or student status $^{(5,7,10)}$, a gap that justifies the engagement in investigations from a gender perspective, but with a universal character regarding health conditions.

\section{OBJECTIVE}

To describe the results of a mental health promotion group conducted by nurses for adult women of the general population (without specific morbidity) in the basic care setting.

\section{METHOD}

\section{Ethical aspects}

The project was approved by the Research Ethics Committee of the University of São Paulo at Ribeirão Preto College of Nursing (USP). It should be emphasized that women who met the established inclusion criteria were clarified regarding the purpose of the study and the nature of data collection. Those who agreed to participate signed the Free and Informed Consent Term (FICF).

\section{Study design, location and period}

This is a pre-and post-test quantitative study whose structure was based on the Checklist of the Strengthening the Reporting of Observational Studies in Epidemiology (Strobe) initiative, which includes recommendations for improving the quality of the description of observational studies ${ }^{(12)}$. Developed in a Basic Health Unit (BHU) in Ribeirão Preto, São Paulo, Brazil. Data collection was performed during the period from February to December 2013.

\section{Population and sample; inclusion and exclusion criteria}

The estimated population under the responsibility of this unit is composed of 14,148 people. Young adults (aged between 25 and 39 years old) correspond to the majority of the population in the territory studied, with regions where people are concentrated in situations of social vulnerability such as families with low income and level of schooling, and others with high levels of violence. In this population, $51.4 \%(7,272)$ were women whose age distribution was: $29.5 \%(2,145)$ from 0 to 19 years old, $65.3 \%(4,752)$ from 20 to 64 years old and $5.1 \%$ (369) from 65 to 94 years. All women from the $\mathrm{BHU}$ area were invited to participate through posters, leaflets and/or a direct approach in-home visits or waiting room of the Unit.

The criteria for inclusion of the women were between 20 and 64 years old and to be a registered user in the BHU in question. 
Women who had a serious health condition that made it impossible to complete the questionnaires were excluded.

The study was developed in four stages: 1) survey of the psychosocial information of the women, 2) performing groups, 3) survey of the psychosocial information of the women at the end of the group, and 4) a new survey three months after ending the group.

In the first stage of the present study, 113 women agreed to participate. Out of these, 71 showed an interest in attending group, and they received home visits for a first reception and explanation about the objectives and beginning of group activities. In the groups (stage 2), 29 women participated in at least one of the meetings, and only nine had $80 \%$ attendance in the groups. These nine were included in subsequent steps, and they were, therefore, the final sample of the present study.

\section{Study protocol}

The intervention protocol used to operationalize the groups was developed by two nurses with experience in the area of mental health, a psychologist, and a nursing student. At the core of the interventions was the Body Mapping technique, which has been used in research and interventions with women in different situations of vulnerability, such as immigrants, victims of violence, HIV patients, hepatitis $C$, among others. This intervention technique, adapted by a Canadian nurse for use as data collection as well, assumes that the experiences are strongly marked in the corporeal plane ${ }^{(13)}$.

Such process, contextualized to the participants'life trajectories and mediated by a nurse able to offer emotional support, can be beneficial to increase the perception of self, the coping potential and, consequently, the self-esteem.

Thus, this technique was used following the recommendations and script recommended for this purpose ${ }^{(13)}$, adapting it to eight steps: real-sized body tracing and impression of a personal symbol or slogan; self-portrait; representation of marks (physical or subjective) on and under the skin; weaknesses and strengths; significant events of childhood, adolescence and adult life; support structures; drawing the future and message to others; body map decoration and narrative about it.

These stages were interspersed by social skills training (assertive speech, relaxation techniques, social support activation strategies), reflection on daily activities and personal emotions using cards with facial expressions (emotion cards) and playful activities for health education (bingo about women's health, quiz about sexuality).

The intervention had ten weekly meetings of approximately one hour and 30 minutes each, and it was held in a room of the Basic Health Unit, in order to facilitate the access of the participants. The themes of each meeting and the strategies used are presented in Chart 1.

The psychosocial indicators adopted were: social support, quality of life, and self-esteem, which have been identified as factors strongly related to women's mental health ${ }^{(14-15)}$. Social support facilitates social coexistence, it facilitates social integration, it fosters behavior change, it reassures self-worth, and it provides assistance. Self-esteem is about valuing and approving oneself; it is described as a set of thoughts and feelings about oneself, conforming to a positive orientation - self-appropriation - or negative-depreciation ${ }^{(16)}$. And the quality of life was considered as a general measure related to satisfaction with life and health.
Chart 1 - Themes, contents and strategies of each meeting, Ribeirão Preto, Brazil, 2013-2014

\begin{tabular}{|c|c|c|}
\hline Meeting & Theme & Strategy \\
\hline $1 \mathrm{st}$ & $\begin{array}{l}\text { The woman } \\
\text { today }\end{array}$ & $\begin{array}{l}\text { Presentation of participants; Group } \\
\text { discussion about the daily life of women in } \\
\text { the contemporary world; Body Mapping: } \\
\text { body tracing, personal symbol or slogan. }\end{array}$ \\
\hline $2 n d$ & Self-esteem & $\begin{array}{l}\text { Emotion cards: emotions and feelings } \\
\text { related to the events of the week; } \\
\text { dynamics using a mirror to self-describe; } \\
\text { Body Mapping: self-portrait. }\end{array}$ \\
\hline $3 r d$ & Self-care & $\begin{array}{l}\text { Emotion cards: emotions and feelings related } \\
\text { to the events of the week; bingo about } \\
\text { women's health; Body Mapping: scars or } \\
\text { subjective marks on and under the skin. }\end{array}$ \\
\hline 4th & $\begin{array}{c}\text { Assertive } \\
\text { communication }\end{array}$ & $\begin{array}{l}\text { Emotion cards: emotions and feelings } \\
\text { related to the events of the week; assertive } \\
\text { communication training using examples } \\
\text { from participants' daily lives; Body } \\
\text { Mapping: weaknesses and strengths. }\end{array}$ \\
\hline 5th & $\begin{array}{l}\text { Personal } \\
\text { trajectory }\end{array}$ & $\begin{array}{l}\text { Emotion cards: emotions and feelings } \\
\text { related to the events of the week; Body } \\
\text { Mapping: significant events in childhood, } \\
\text { adolescence, and adulthood. }\end{array}$ \\
\hline 6th & Sexuality & $\begin{array}{l}\text { Emotion cards: emotions and feelings } \\
\text { related to the events of the week; quiz about } \\
\text { sexuality; questioning and discussion. }\end{array}$ \\
\hline 7th & Social support & $\begin{array}{l}\text { Emotion cards: emotions and feelings } \\
\text { related to the events of the week; Body } \\
\text { Mapping: social support structures; } \\
\text { Techniques of activation of social support. }\end{array}$ \\
\hline 8th & Stress coping & $\begin{array}{l}\text { Emotion cards: emotions and feelings } \\
\text { related to the events of the week; } \\
\text { discussion of the most recent stressors; } \\
\text { relaxation techniques. }\end{array}$ \\
\hline 9th & $\begin{array}{c}\text { Thinking about } \\
\text { the future }\end{array}$ & $\begin{array}{l}\text { Emotion cards: emotions and feelings related } \\
\text { to the events of the week; discussion of } \\
\text { the outlook for the future; Body Mapping: } \\
\text { Drawing the future and message to others. }\end{array}$ \\
\hline 10th & Final meeting & $\begin{array}{l}\text { Emotion cards: emotions and feelings } \\
\text { related to the events of the week; } \\
\text { feedback from the participants about the } \\
\text { group; Body Mapping: decoration and } \\
\text { personal narratives. }\end{array}$ \\
\hline
\end{tabular}

In order to evaluate these indicators, we used psychometric scales validated for use in Brazil, namely the Sarason Social Support Questionnaire (SSQ), the World Health Organization Quality of Life Assessment tool, abbreviated version (WHOQOL-bref) and the Rosenberg Self-Esteem Scale.

Regarding the sociodemographic questionnaire, questions were added in the questionnaire formulation, covering aspects related to education and living conditions, family, color or ethnicity, work, and income.

The SSQ (Cronbach's a is 0.97 for SSQ-N and 0.94 for SSQ-S) is an instrument developed to quantify the availability of perceived support. It allows identifying the composition of the support network of the individual, considering the type of relationship of the participant with these supporters (friends, relatives) and 
the degree of satisfaction with this support. The scale, already validated in Brazil, provides two scores, one concerning the number of supporters and one about satisfaction: the higher the score, the greater the perception of support ${ }^{(17)}$.

The WHOQOL-bref (Cronbach's $a=0.89$ ) is composed of 26 questions covering four domains: 1-physical; 2-psychological; 3-social relations; 4-environment. The Portuguese version has also been validated for use in Brazil. Regarding the scores, there is a syntax for the final calculation that provides six scores, one on the perception of the quality of life in general, one on satisfaction with health and one for each domain of the scale ${ }^{(18)}$.

The Rosenberg Self-esteem Scale (Cronbach's a $=0.90$ ) is one of the most used instruments in the self-esteem studies available in international literature. It consists of a one-dimensional measure, and it is composed of ten statements about the set of feelings of self-esteem and self-acceptance. Each affirmative contains items graded with the Likert scale ranging from one to four points that indicate the individual's agreement or not with each statement (I totally agree, I agree, I disagree, I strongly disagree), so that the higher the score, the higher the self-esteem ${ }^{(16)}$.

The instruments were applied in three different times: before the intervention, immediately after and three months after the end of the intervention. The time for each application was approximately 45 minutes.

\section{Analysis of results and statistics}

The data were analyzed using the Friedman Test, which is a nonparametric test indicated for analyzes with more than two related samples ${ }^{(19)}$. The hypothesis tested was the increase or decrease of the scores of each psychosocial indicator over time (before, immediately after and after three months). A significance level of $\mathrm{p}<0.05$ and a $95 \%$ confidence interval $(\mathrm{Cl})$ were considered. The analyses were undertaken using SPSS software version 17.0.

\section{RESULTS}

The nine participants had, on average, 43 years old (standard deviation of 12.7). Five were black or brown, and four were white. Six were married, two unmarried or divorced, and as for the number of children, two had no children, one had one, and the other had two or four children.

On schooling, three participants had completed primary education, four the secondary one, and one was finishing the graduation. Three of them reported working for themselves and four were unemployed. As for family income, five participants reported income of two to five minimum wages, one of one to two minimum wages, and two did not report income.

Although it was not an inclusion criterion, all participants mentioned some vulnerable situation: three were victims of domestic violence, three had a mental disorder (depression or anxiety disorder), two reported family problems and one, chronic disease (sequelae of a stroke).

The mean scores for social support and self-esteem are presented in Figures 1 and 2. Figure 1 shows that social support (satisfaction and number of supporters) increased after the intervention, and it remained throughout the three months with slight oscillation.
Self-esteem increased after the intervention (Figure 2), but this result was not maintained until the third questionnaire was applied.

The domains of quality of life that increased after the intervention were the physical, social, and environmental relations, the psychological domain was maintained throughout the follow-up (Figure 3).

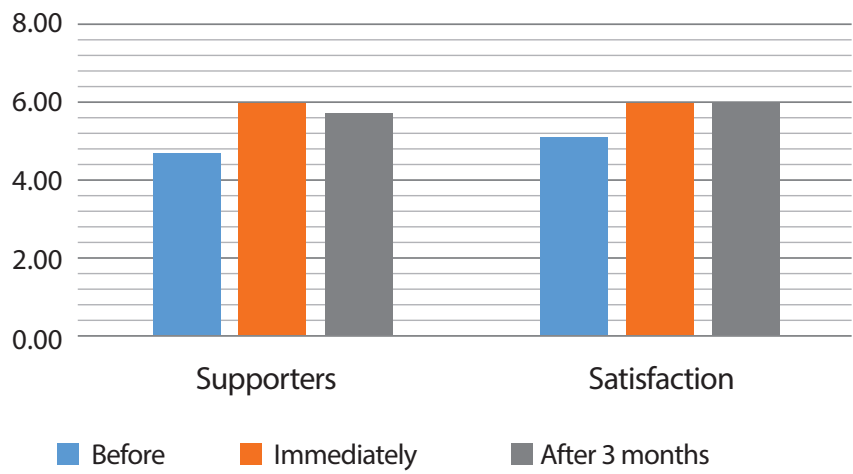

Figure 1 - Mean of social support scores (satisfaction and number of supporters) before, immediately after and three months after the intervention, $\mathrm{n}=$ 9, Ribeirão Preto, Brazil, 2013-2014

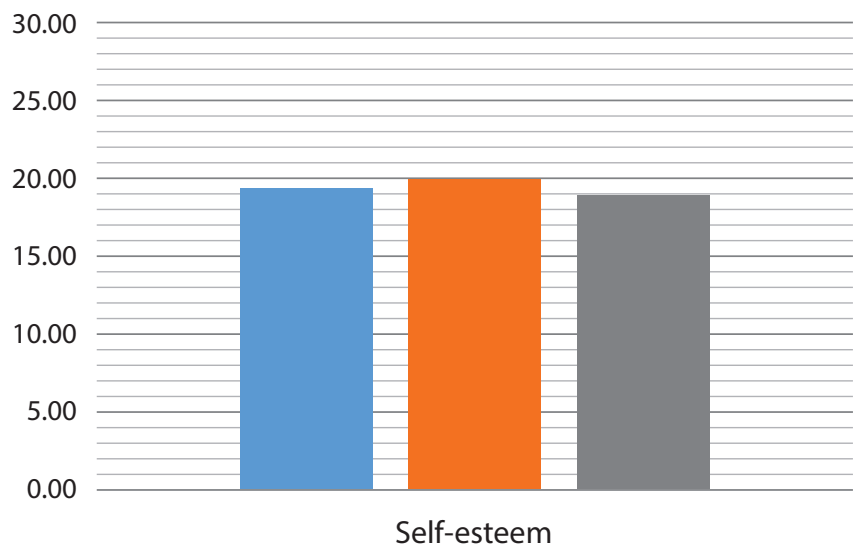

Before $\square$ Immediately $\quad$ After 3 months

Figure 2 - Mean of the self-esteem score before, immediately after and three months after the intervention, $n=9$, Ribeirão Preto, Brazil, 2013-2014

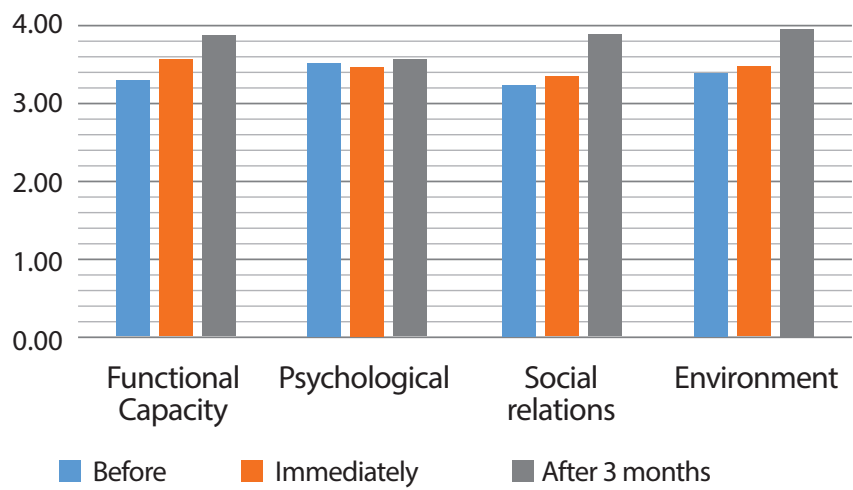

Figure 3 - Mean of quality of life scores before, immediately after and three months after the intervention, $n=9$, Ribeirão Preto, Brazil, 2013-2014

Although the descriptive data indicated such results, there was no statistically significant difference in relation to pre- and post-evaluation for the number of supporters, satisfaction with 
support, and self-esteem. Regarding the quality of life, the difference between the pre- and post-evaluation periods was significant in the physical and environmental domains (Table 1).

Table 1 - Results obtained from the Friedman Test, $n=9$, Ribeirão Preto, Brazil, 2013-2014

\begin{tabular}{|c|c|c|c|c|c|}
\hline \multirow{2}{*}{ Indicadores } & \multirow[b]{2}{*}{ Before } & \multicolumn{2}{|c|}{ Average rank } & \multirow{2}{*}{$\mathbf{X}^{2}$} & \multirow{2}{*}{$\underset{\text { value }}{p}$} \\
\hline & & After & After 3 months & & \\
\hline Number of supporters & 1.83 & 2.06 & 2.11 & 0.452 & 0.798 \\
\hline Satisfaction with support & 1.89 & 1.72 & 2.39 & 2.600 & 0.273 \\
\hline \multicolumn{6}{|l|}{ Quality of life } \\
\hline Physical domain & 1.44 & 1.89 & 2.67 & 7.294 & 0.026 \\
\hline Psychological domain & 2.00 & 1.78 & 2.22 & 1.067 & 0.587 \\
\hline Social relations domain & 1.94 & 1.67 & 2.39 & 2.966 & 0.227 \\
\hline Environmental domain & 1.33 & 1.83 & 2.83 & 11.455 & 0.003 \\
\hline Self-esteem & 1.67 & 2.06 & 2.28 & 1.771 & 0.412 \\
\hline
\end{tabular}

\section{DISCUSSION}

Among the participants in the study, most of them presented low schooling, unemployment, and they declared themselves to be black or brown, which are characteristics that, along with the other vulnerabilities mentioned by them, increase the likelihood of the development or aggravation of mental disorders or psychic suffering ${ }^{(2,20)}$.

The descriptive results of the present study show that, after the three-month follow-up, there was a small decrease in self-esteem and increase in the scores of all other indicators, but these changes did not present statistical significance. Despite this, there was a significant difference between the pre-and post-evaluation in the physical domain of quality of life, which contains items related to the functional capacity and environmental domain of the quality of life that includes aspects related to the environment at home, access to leisure, information, and health and social care.

Interventions to promote women's mental health have been described as effective to expand the social support network, helping with stress management, and reducing emotional distress among women $^{(10,21)}$. The descriptive results of the present study indicate a possible improvement in most of the indicators used, however, it was identified that such changes were not statistically significant, corroborating a previous study ${ }^{(10)}$ that describes as possible causes of such results the difficulty of adherence of women who need more help, the time needed to incorporate skills and the subjective aspects that cannot be measured solely by the quantitative data.

On the other hand, the results of the present study also contradict the evidence from other research that demonstrated that mental health promotion interventions had favorable outcomes in terms of increased support ${ }^{(6,9)}$. This result may indicate either inadequacy of this intervention protocol in relation to the proposed purpose or the inadequacy of the choice of psychosocial indicators. That is, since promoting mental health aims to strengthen resilience, promote emotional well-being, strengthen social bonds, and increase social capital ${ }^{(1-3)}$, some indicators that could be more sensitive to the proposal of the present study would be self-efficacy, coping styles, symptoms of common mental disorders, other dimensions of social support and access to resources in the network.
Increasing individuals' ability to have control over their lives is also an important goal of promoting mental health ${ }^{(2)}$. Therefore, the physical domain of the quality of life scale adopted in the present study, which also measures the functional capacity of individuals, was presented as an important indicator. This domain covers issues related to pain and discomfort; energy and fatigue; sleep and rest; mobility; daily activities; drug treatment and dependence; and ability to work ${ }^{(18)}$.

Some previous studies on psychosocial interventions focused on the promotion of mental health have shown improvement in the perception of the quality of life of the participants ${ }^{(7,9)}$, and one of these studies presented positive results only in the physical domain ${ }^{(11)}$, similarly to the present study. In this sense, other studies point to the effectiveness of actions to promote mental health in improving worker productivity ${ }^{(1)}$, increasing the sense of care ${ }^{(2)}$, improving treatment management ${ }^{(4)}$, and social functioning ${ }^{(7,9)}$, which also correspond to the functional capacity of the subjects.

It should be noted that some of the activities proposed during the meetings were directly related to the facets of the physical domain, for example, the discussion of daily activities, relaxation techniques and health education using ludic strategies. In addition, the Body Mapping technique has been described as an important promoter of physical and corporal perception improvement ${ }^{(22)}$.

Studies with interventions to improve the physical domain among vulnerable women point to support groups involving ludic activities, relaxation, and health education activities as effective ${ }^{(23-24)}$. Thus, the improvement of the physical domain could indicate a possible effect of these techniques.

Another relevant indicator according to the present study concerns the environmental domain, which covers issues related to physical safety and protection, home environment, financial resources, availability of transportation, health and social care, leisure opportunities and to acquire new information and skills, as well as the quality of the physical environment ${ }^{(18)}$.

Previous studies that address issues related to body image ${ }^{(25)}$ and body and mind integration ${ }^{(26)}$ have identified the association of these aspects with the physical and environmental domains of quality of life. These results corroborate the discussion of the findings of the present study since the proposed intervention was based both on a body-focused approach (physical and subjective) and on a perspective of integrating emotions, feelings and actions.

It is worth emphasizing that, given the social emphasis of the environmental domain, there is a recommendation for a change in the focus of individual mental health. Therefore, issues of housing, safety, leisure, and other resources related to the basic needs at the community level (items in the environment domain of quality of life) should be integrated into care planning and mental health promotion strategies ${ }^{(27)}$.

In this sense, it should be mentioned that a review study, related to nursing teaching, has discussed two important dimensions of care, namely: competent provision of clinical care and offering emotional support ${ }^{(28)}$. It is suggested, based on the results of the present study, that nursing, especially in the primary care area, assign to its practice a "third dimension" of care that would be the socio-community, prioritizing more collective approaches, including mental health promotion. 
In the present study, in three months, three women started professional courses and two engaged in paid activities, considered as extremely positive, given their socioeconomic status. It is understood that such engagement refers both to the item "opportunities to acquire new skills" (environment domain) and to the item "functional capacity" (physical domain), suggesting the effectiveness of the intervention used in this sense.

Regarding the indicators that did not present significant results, it cannot be disregarded that the evaluation of actions to promote mental health is extremely complex, due to the subjectivity involved and the different factors that may interfere in the results ${ }^{(2)}$. In addition, the present study was a pilot study, which allows several adjustments to be made before undertaking it in the form of a randomized controlled trial.

Adherence to group intervention was the greatest challenge encountered, that is, a small number of women participated in at least $80 \%$ of the meetings. In this sense, it is emphasized that, although the group design further optimizes the resources, it can be less effective to handle intimate and psychological aspects, especially among women in situations of social or psychological vulnerability, that is, a more private environment or individual approaches may be necessary in these cases. This fact has relevance in the present study since the difficulties of daily life presented by women were related to complex issues such as conjugal conflicts, domestic violence, problems with the neighborhood. Besides, the participants lived in the same neighborhood, and they knew each other. These aspects possibly contributed to the low adherence in the group.

\section{Study limitations}

Regarding the main limitations of the study, the sample size and the non-experimental design are pointed out. Additionally, the choice of psychosocial indicators may not have been as effective, considering the objectives of the intervention proposal.

\section{Contributions to the area of nursing, health or public policy}

The present study raises important reflections regarding nursing, mainly in the sense of emphasizing the role of this professional in the promotion of mental health of the population and that such action can also be performed by generalist nurses, since during the undergraduate course basic skills are developed to act in this area through group or individual approaches. The results of the present study show the challenges of group approaches and the importance of selecting good evaluation indicators. On the other hand, they present an innovative intervention protocol useful to improve well-being, also in the setting of primary health care, especially considering the relation of the users with their own body and their functional capacity.

\section{CONCLUSION}

The proposition that a group with psychosocial interventions to promote mental health could increase the self-esteem and perception of social support of women attended in the primary care was not confirmed by the present study.

Nevertheless, significant results in the physical and environmental domains related to functional capacity and opportunities to acquire new skills, respectively, suggest that ludic activities and the Body Mapping technique can be promising, especially to improve the relationship between women and their own bodies and the environment in which they live.

Thus, interventions can be an important tool for nursing practice, increasing the supply of mental health actions in the setting of primary health care, mainly because the physical and emotional aspects are complementary in the health-disease process and, coupled with an integrated approach to the needs of the community, will certainly reflect positively on women's mental health.

\section{REFERENCES}

1. Enns J, Homqvist M, Wener P, Halas G, Rothney J, Schultz A, et al. Mapping interventions that promote mental health in the general population: a scoping review of reviews. Prev Med. 2016;87:70-80. doi: 10.1016/j.ypmed.2016.02.022

2. Kalra G, Christodoulou G, Jenkins R, Tsipas V, Christodoulou N, Lecic-Tosevski D, et al. Mental health promotion: guidance and strategies. Eur Psychiatry. 2012;27(2):81-6. doi: 10.1016/j.eurpsy.2011.10.001

3. Fernandez A, Moreno-Peral P, Zabaleta-del-Olmo E, Bellon JA, Aranda-Regules JM, Luciano JV, et al. Is there a case for mental health promotion in the primary care setting? A systematic review. Prev Med. 2015;76:S5-11. doi: 10.1016/j.ypmed.2014.11.019

4. Armando M, Pontillo M, Vicari S. Psychosocial interventions for very early and early-onset schizophrenia: a review of treatment efficacy. Curr Opin Psychiatr. 2015;28(4):312-23. doi: 10.1097/YCO.0000000000000165

5. Jones LV, Ahn S, Chan KT. Expanding the psychological wellness threshold for black college women an examination of the claiming your connections intervention. Res Soc Work Pract. 2014;26(4):399-411. doi: 10.1177/1049731514549631

6. Ahmed K, Marchand E, Williams V, Coscarelli A, Ganz PA. Development and pilot testing of a psychosocial intervention program for young breast cancer survivors. Patient Educ Couns. 2016;99(3):414-20. doi: 10.1016/j.pec.2015.09.014

7. Kaaya SF, Blande J, Antelman G, Cyprian F, Emnos KM, Matsumoto K, et al. Randomized controlled trial evaluating the effect of an interactive group counseling intervention for HIV positive women on prenatal depression and disclosure of HIV status. AIDS Care. $2013 ; 25(7): 854-62$. doi: 10.1080/09540121.2013.763891

8. Schulz AJ, Israel BA, Mentz GB, Bernal C, Caver D, DeMajo R, et al. Effectiveness of a walking group intervention to promote physical activity and cardiovascular health in predominantly non-hispanic black and hispanic urban neighborhoods: findings from the walk your heart to health intervention. Health Educ Behav. 2015;42(3):380-92. doi: 10.1177/1090198114560015 
9. Fawzi MCS, Eustache E, Oswald C, Louis E, Surkan PJ, Scanlan F, et al. Psychosocial support intervention for HIV-affected families in Haiti: implications for programs and policies for orphans and vulnerable children. Soc Sci Med. 2012;74(10):1494-503. doi: 10.1016/j. socscimed.2012.01.022

10. Momino K, Mitsunori M, Yamashita H, Toyama T, Sugiura H, Yoshimoto N, et al. Collaborative care intervention for the perceived care needs of women with breast cancer undergoing adjuvant therapy after surgery: a feasibility study. Jpn J Clin Oncol. 2017;47(3):213-20. doi: 10.1093/jjco/hyw189

11. Lerma A, Perez-Grovas H, Bermudez L, Peralta-Pedrero ML, Robles-García R, Lerma C. Brief cognitive behavioural intervention for depression and anxiety symptoms improves quality of life in chronic haemodialysis patients. Psychol Psychother. 2017;90(1):105-23. doi: 10.1111/ papt.12098

12. Malta M, Cardoso LO, Bastos FI, Magnanini MMF, Silva CMFP. STROBE initiative: guidelines on reporting observational studies. Rev Saúde Pública. 2010;44(3):559-65. doi: 10.1590/S0034-89102010000300021

13. Gastaldo D, Magalhães L, Carrasco C, Davy C. Body-map storytelling as research: methodological considerations for telling the stories of undocumented workers through body mapping [Internet]. Toronto: University of Toronto; 2012 [cited 2017 May 28]. Available from: http:// www.migrationhealth.ca/undocumented-workers-ontario/body-mapping

14. Mota NP, Medved M, Whitney D, Hiebert-Murphy D, Sareen J. Protective factors for mental disorders and psychological distress in female, compared with male, service members in a representative sample. Can J Psychiatry. 2013;58(10):570-8. doi: 10.1177/070674371305801006

15. Manuel Jl, Martinson ML, Bledsoe-Mansori SE, Bellamy JL. The influence of stress and social support on depressive symptoms in mothers with young children. Soc Sci Med. 2012;75(11):2013-20. doi: 10.1016/j.socscimed.2012.07.034

16. Hutz CS, Zanon C. Revisão da apadtação, validação e normatização da escala de autoestima de Rosenberg. Aval Psicol [Internet]. 2011 [cited 2017 Apr 12];10(1):41-9. Available from: http://pepsic.bvsalud.org/scielo.php?script=sci_arttext\&pid=S1677-04712011000100005\&lng=pt

17. Matsukura TS, Marturano EM, Oishi J. O Questionário de Suporte Social (SSQ): estudos da adaptação para o português. Rev Latino-Am Enferm. 2002;10(5):675-81. doi: 10.1590/S0104-11692002000500008

18. Fleck MP, Louzada S, Xavier M, Chachamovich E, Vieira G, Santos L, et al. Aplicação da versão em português do instrumento abreviado de avaliação da qualidade de vida "WHOQOL-bref". Rev Saúde Pública. 2000;34(2):178-83. doi: 10.1590/S0034-89102000000200012

19. Brace N, Kemp R, Snelgar E. SPSS for psychologists. $5^{\text {th }}$ ed. New York: Routledge; 2013.

20. Chandra PS, Sowmya HR, Mehrotra S, Duggal M. "SMS" for mental health: feasibility and acceptability of using text messages for mental health promotion among young women from urban low-income settings in India. Asian J Psychiatr. 2014;11:59-64. doi: 10.1016/j. ajp.2014.06.008

21. Thomas M, Vieten C, Adler N, Ammondson I, Coleman-Phox K, Epel E, et al. Potential for a stress reduction intervention to promote healthy gestational weight gain: focus groups with low-income pregnant women. Womens Health Issues. 2014;24(3):e305-11. doi: 10.1016/j. whi.2014.02.004

22. Gastaldo D, Carrasco C, Magalhaes L. Entangled in a web of exploitation and solidarity: Latin American undocumented workers in the Greater Toronto Area [Internet]. Toronto: University of Toronto; 2012 [cited 2017 Jun 30]. Available from: http://www.migrationhealth.ca/ undocumented-workers-ontario/summary-findings

23. Björneklett HG, Lindemalm C, Ojutkangas ML, Berglund A, Letocha $H$, Strang $P$, et al. A randomized controlled trial of a support group intervention on the quality of life and fatigue in women after primary treatment for early breast cancer. Support Care Cancer. 2012;20(12):3325-34. doi: 10.1007/s00520-012-1480-1

24. Badger T, Segrin C, Pasvogel A, Lopez AM. The effect of psychosocial interventions delivered by telephone and videophone on quality of life in early-stage breast cancer survivors and their supportive partners. J Telemed Telecare. 2013;19(5):260-5. doi: 10.1177/1357633X13492289

25. Skopinski F, Resende TL, Schneider RH. Body image, mood and quality of life. Rev Bras Geriatr Gerontol. 2015;18(1):95-105. doi: 10.1590/1809-9823.2015.14006

26. Portugal FB, Campos MR, Correia CR, Gonçalves DA, Ballester D, Tófoli LF, et al. Social support network, mental health and quality of life: a cross-sectional study in primary care. Cad Saúde Pública. 2016;32(12):e00165115. doi: 10.1590/0102-311x00165115

27. Williams E, Sands N, Elsom S, Prematunga RK. Mental health consumers' perceptions of quality of life and mental health care. Nurs Health Sci. 2015;17(3):299-306. doi: 10.1111/nhs.12189

28. Leonard L. Emotional displays: Nurse educators engaging and reflecting on their own emotional displays in preparing nursing students for the emotional complexities of nursing practice. Nurs Educ Pract. 2017;26:21-6. doi: 10.1016/j.nepr.2017.06.001 